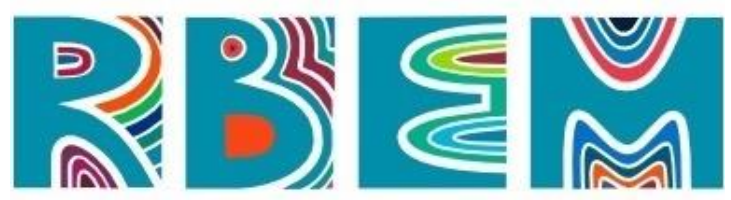

REVISTA BAIANA DE EDUCAÇÃO MATEMÁtICA

$\underline{\text { ARTIGO }}$

do] https://doi.org/10.47207/rbem.v2i01.12320

\title{
O Estágio Supervisionado na Formação Inicial do Professor: A experiência em uma escola municipal de São Paulo e os seus desafios em Tempos Pandêmicos
}

\author{
SILVA, Flavio Medeiros \\ Secretaria da Educação do Município de São Paulo (SME). Pós-graduado Práticas de Letramento e \\ Alfabetização. ORCID: https://orcid.org/0000-0001-9296-6758. E-mail: flandes4@ gmail.com. \\ BORELLI, Suzete de Souza \\ Universidade Cruzeiro do Sul (UNICSUL). Doutora Ensino de Ciências e Matemática. ORCID: \\ https://orcid.org/0000-0002-738-8162. E-mail: suzeteborelli@gmail.com.
}

\begin{abstract}
Resumo: A pandemia de COVID 19 alterou o modo de vida de todas as pessoas, interferindo na economia, política, educação e sociedade como um todo. Devido a esse novo fenômeno a humanidade passou a rever as suas ações, buscando cumprir protocolos sanitários para preservar a saúde humana. Nesse movimento as instituições de ensino passaram a se adequar a esse novo momento incorporando o ensino remoto mediado pelas tecnologias. Nesse novo contexto a atividade do estágio supervisionado passou a se adequar a essa nova realidade. O presente artigo perpassa pela investigação sobre a importância do estágio supervisionado na formação dos futuros professores e a perspectiva dessa prática em tempos de educação remota. Nessa perspectiva analisou-se a significativa experiência de estágio supervisionado desenvolvido numa escola pública no contexto da pandemia. A partir dessa perspectiva, o artigo trilha um percurso metodológico de questionamentos sobre o estágio supervisionado, perpassando pela análise bibliográfica, por meio da investigação de estudos publicados de autores que abordam a temática. Por meio deste trabalho identificou-se a contribuição significativa do estágio supervisionado na formação do futuro professor, como uma ação que relaciona teoria e prática, possibilitando um processo formativo que colabore com a atuação docente e a prática pedagógica do futuro professor.
\end{abstract}

Palavras-chave: Estágio Supervisionado. Formação de Professores. Educação Remota.

\section{The Supervised Internship in Initial Teacher Education: The experience in a municipal school in São Paulo and its challenges in Pandemic Times}

\begin{abstract}
The COVID 19 pandemic changed the way of life of all people, interfering with the economy, politics, education and society as a whole. Due to this new phenomenon, humanity began to review its actions, seeking to comply with sanitary protocols to preserve human health. In this movement, educational institutions began to adapt to this new moment, incorporating remote learning mediated by technologies. In this new context, the supervised internship activity began to adapt to this new reality. This article permeates the investigation of the importance of supervised training in the training of future teachers and the perspective
\end{abstract}




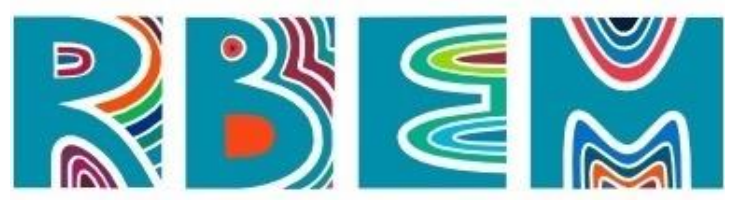

REVISTA BAIANA DE EDUCAÇÃO MATEMÁTICA

of this practice in times of remote education. From this perspective, the significant experience of supervised internship developed in a public school in the context of the pandemic was analyzed. From this perspective, the article follows a methodological path of questioning about the supervised internship, passing through the bibliographic analysis, through the investigation of published studies by authors who address the theme. Through this work, the significant contribution of the supervised internship in the formation of the future teacher was identified, as an action that relates theory and practice, enabling a training process that collaborates with the teaching performance and pedagogical practice of the future teacher.

Keywords: Supervised internship. Teacher training. Remote Education.

\section{El Internado Supervisado en Formación Docente Inicial: La experiencia en una escuela municipal de São Paulo y sus desafíos en Pandemic Times}

Resumen: La pandemia de COVID 19 cambió la forma de vida de todas las personas, interfiriendo con la economía, la política, la educación y la sociedad en su conjunto. Debido a este nuevo fenómeno, la humanidad comenzó a revisar sus acciones, buscando cumplir con los protocolos sanitarios para preservar la salud humana. En este movimiento, las instituciones educativas comenzaron a adaptarse a este nuevo momento, incorporando el aprendizaje a distancia mediado por tecnologías. En este nuevo contexto, la actividad de prácticas supervisadas comenzó a adaptarse a esta nueva realidad. Este artículo permea la investigación de la importancia de la formación supervisada en la formación de futuros profesores y la perspectiva de esta práctica en tiempos de educación a distancia. Desde esta perspectiva, se analizó la experiencia significativa de pasantía supervisada desarrollada en una escuela pública en el contexto de la pandemia. Desde esta perspectiva, el artículo sigue un camino metodológico de cuestionamiento sobre la pasantía supervisada, pasando por el análisis bibliográfico, a través de la investigación de estudios publicados por autores que abordan el tema. A través de este trabajo se identificó el aporte significativo de la pasantía supervisada en la formación del futuro docente, como una acción que relaciona teoría y práctica, posibilitando un proceso de formación que colabore con el desempeño docente y la práctica pedagógica del futuro docente.

Palavras-Clave: Pasantía supervisada. Formación de profesores. Educación a distancia

\section{Introdução}

A formação dos futuros professores é uma temática relevante no campo educacional, objeto de diversas pesquisas e preocupações na área acadêmica, na política e sociedade. Pensar nessa formação perpassa também pela construção de um profissional competente e preparado para enfrentar os desafios da docência e da sala de aula. No contexto hodierno a humanidade vivencia um mundo que sofre intensas transformações, num cenário de incertezas 


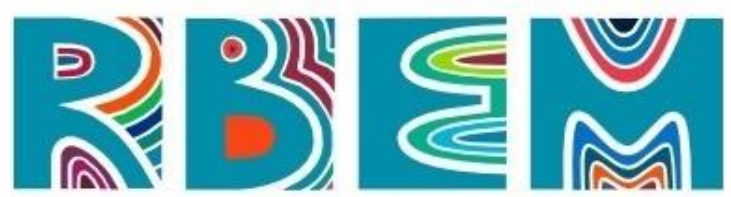

REVISTA BAIANA DE EDUCAÇÃO MATEMÁTICA

nos diversos aspectos da vida humana. Ser um profissional do século XXI perpassa pela construção de múltiplas habilidades e de preparo para lidar com o inesperado, com a pluralidade e os intensos desafios do contexto atual.

Na reflexão sobre a formação do futuro docente se apresenta a necessidade da intensa relação entre a teoria e a prática profissional. A formação teórica perpassou e ainda perpassa de forma dominante na formação do futuro professor. Essa formação é sem dúvida necessária, mas necessita ser ressignificada no campo da prática. De nada adianta dominar um conteúdo se não se sabe como aplicar ou ensinar no contexto da escola, observando o estudante real. Dentro dessa perspectiva o estágio supervisionado se apresenta como uma etapa obrigatória nos cursos de licenciatura e como um momento significativo de formação ao qual o graduando passa a ter contato com o campo de trabalho, buscando relacionar o que se aprende na universidade com o campo profissional.

A legislação relacionada ao estágio supervisionado, traz como premissa a necessidade de formação dos futuros professores. O presente artigo investiga por meio do estudo bibliográfico as potencialidades do estágio supervisionado na formação do futuro professor e o desafio dessa prática no contexto da pandemia de COVID - 19 ilustrada com a experiência de estágio na educação remota em uma escola da Rede Municipal de São Paulo.

Nesse sentido, podemos nos perguntar, se a experiência em contexto remoto tem propiciado o desenvolvimento do estágio curricular? Quais os desafios apresentados a vivência do estágio no contexto pandêmico que acarretou o desenvolvimento do ensino remoto? Esses questionamentos vão nos guiar para refletirmos sobre a prática de estágio na formação docente.

A organização do texto no decorrer do artigo perpassa pela apresentação do percurso metodológico, a exigência do estágio supervisionado e a legislação imbuída nessa prática. Em seguida aborda reflexões sobre as contribuições do estágio supervisionado na formação docente, respaldando essa análise em Almeida e Pimenta (2014), Teixeira e Cyrino (2013), Imbernón (2014) e Libâneo (1999). Posteriormente trata sobre a prática do estágio supervisionado no contexto da educação remota, trazendo a experiência de acolhimento dos estagiários numa escola pública de São Paulo. Em seguida apresenta alguns desafios e entraves para a prática do estágio supervisionado e por fim apresenta algumas considerações finais por meio desse estudo. 


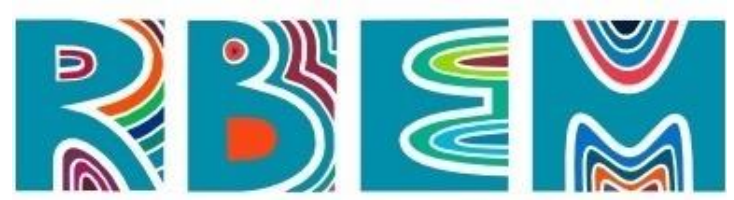

\section{Metodologia}

Diante da importância da formação inicial dos futuros professores e a questão do estágio supervisionado como uma prática necessária e presente na legislação e no projeto pedagógico dos cursos de licenciatura, esse artigo se fundamenta na necessidade de trazer reflexões a respeito do estágio supervisionado na formação dos futuros professores e o desafio dessa prática no contexto pandêmico e da educação remota.

A partir dessa perspectiva, o artigo trilha um percurso metodológico de questionamentos sobre o estágio supervisionado, perpassando pela análise bibliográfica, por meio da investigação de estudos publicados de autores que abordam a temática, como a análise de experiências envolvendo o estágio supervisionado no momento pandêmico, trazendo a experiência de uma escola municipal com relação a acolhida de estagiários e a forma como esse se desenvolve no contexto educativo.

Nesse processo, buscamos trazer uma reflexão e diálogo de autores (Severino, 2007; Lakatos e Marconi, 2010) que tratam da pesquisa bibliográfica de maneira que possamos confrontar os dados coletados, revisitar as contribuições teóricas e construir reflexões pertinentes que nos ajude a pensar as questões apresentadas nesse artigo, de forma a compreender melhor as perguntas que foram levantas para essa reflexão, permitindo uma contribuição a comunidade acadêmica e educativa. Nesse sentido concordamos com Rios (2014, p. 119), “A pesquisa constitui-se como espaço de partilha de ideias, de levantamento de questões comuns e de descoberta de especificidades e diferenças, portanto favorecedora de diálogo".

Em seguida discutiremos a algumas exigências relacionadas ao estágio supervisionado.

\section{A Exigência do Estágio Supervisionado}

A formação dos futuros profissionais em qualquer área é uma grande responsabilidade. Pensar nesse processo formativo é fundamental para a qualificação dos futuros profissionais no mercado de trabalho. O campo profissional a cada dia está mais exigente e concorrido, demandando profissionais qualificados, abertos as novas transformações e tecnologias, que saibam inovar e acompanhar as necessidades hodiernas. Lima (2006, p. 35) afirma que 


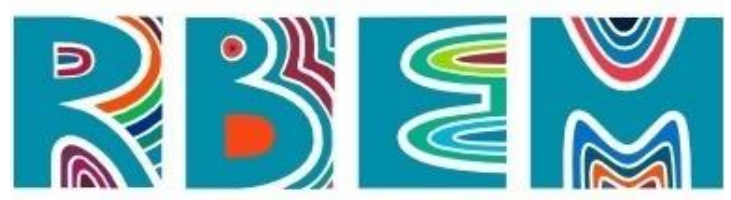

REVISTA BAIANA DE EDUCAÇÃO MATEMÁTICA

"o mundo atual requer um novo tipo de profissional, cujos saberes sejam polivalentes e, sobretudo, amplos e sólidos, para corresponder às peculiaridades e ao caráter multifacetado da prática pedagógica". Pensar nessa formação ultrapassa a concepção de garantir um diploma ou aumentar o número de diplomados, mas preparar um profissional capacitado que desenvolva competências e habilidades essenciais para o desenvolvimento significativo do trabalho.

Apenas a formação teórica do futuro profissional não atende as demandas do mercado de trabalho e dos novos desafios a que se impõem. O estágio supervisionado é uma disciplina presente na carga horária e na formação do futuro professor para enfrentar os desafios da sala de aula. Na observação e interação com o campo de trabalho, o estagiário estabelece um diálogo constante entre as teorias aprendidas relacionadas ao ensino com a prática de sala de aula, refletindo sobre ela, problematizando aquilo que aprende e antecipando o desenvolvimento de atitudes e comportamentos profissionais, ampliando o seu senso crítico e a criatividade, permitindo a aprendizagem sobre a docência no campo prático.

O Estágio, segundo a literatura científica da área de formação de professores, constitui um momento fecundo para a construção da identidade e para os saberes e práticas da docência. É no encontro com as diversas situações do cotidiano da escola, seja em sala de aula, seja no diálogo com os professores e/ou participação nas atividades de planejamento, reuniões, oficinas, que os estagiários vão construindo a sua identidade docente bem como aprendizagens que serão mobilizadas enquanto futuros professores. Estas aprendizagens perspectivam-se em práticas formativas que fomentam a reflexão, o questionamento e a investigação com vistas a estudar, analisar, problematizar, enfim, a desenvolver projetos de intervenção envolvendo as relações e práticas heterogêneas do contexto escolar da educação básica. (SARMENTO, ROCHA, PANIAGO, 2019, p 153)

A Lei $\mathrm{n}^{\circ} 11.788$, de 25 de setembro de 2008, apresenta o estágio como o ato educativo escolar supervisionado, sendo uma prática que deve ocorrer no ambiente de trabalho, com o objetivo de preparação do estudante para a prática profissional. O estágio supervisionado compõe o itinerário formativo do educando, como deve estar proposto no projeto pedagógico do próprio curso. Nessa perspectiva, Fiorentini e Castro (2003, p. 125) apresentam que "Mergulhar no mundo da prática profissional, com valores, saberes e imagens adquiridas ao longo da vida e como aluno representa, para o estagiário, um momento de risco, uma aventura ou uma viagem por um caminho - o de professor - ainda pouco conhecido e vivido". A lei $\mathrm{n}^{\circ}$. 


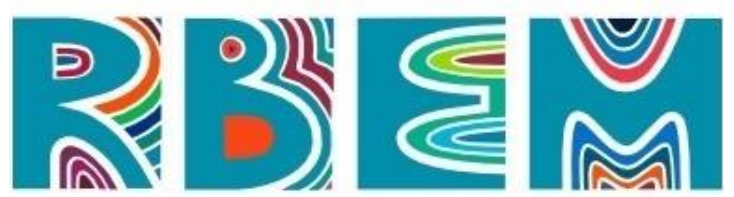

REVISTA BAIANA DE EDUCAÇÃO MATEMÁTICA

11.788 de 2008, aprovada pelo Congresso Nacional, que trata sobre a questão do estágio apresenta em seu artigo $1^{\circ}$ uma definição a respeito.

Art. $1^{\circ}$. Estágio é ato educativo escolar supervisionado, desenvolvido no ambiente de trabalho, que visa à preparação para o trabalho produtivo de educandos que estejam frequentando o ensino regular em instituições de educação superior, de educação profissional, de ensino médio, da educação especial e dos anos finais do ensino fundamental, na modalidade profissional da educação de jovens e adultos. (BRASIL, 2008)

A referida lei determina o estágio como parte integrante das matrizes curriculares dos cursos de licenciatura, sendo obrigatório para a conclusão do curso. A lei dispõe no artigo $3^{\circ}$ a obrigatoriedade da presença de professores orientadores na instituição de ensino, como da concedente do estágio. Aqui se apresenta a importância desse estágio ser supervisionado, onde os professores orientadores vão acompanhar o estagiário, colaborando na formação e reflexão desse em relação a essa experiência acadêmica- profissional.

Esta mesma lei apresenta um ordenamento legal sobre a prática de estágio, indicando em sua organização a necessidade do desenvolvimento de estratégias que tenham o estágio com planos estruturados e condizentes com a realidade escolar e profissional, permitindo uma preparação do estudante para enfrentar os desafios do mundo do trabalho e assim, garantir um processo formativo muito mais significativo. Conforme Pimenta e Lima, é intenção do estágio, desenvolver "atividades que possibilitem o conhecimento, a análise, a reflexão do trabalho docente, das ações docentes, nas instituições, a fim de compreendê-las em sua historicidade, identificar seus resultados, os impasses que apresentam as dificuldades" (PIMENTA; LIMA, 2011, p. 55).

Lisovski e Terrazan (2006, p.2) indicam que "é no exercício da profissão que se consolida o processo de tornar-se professor, ou seja, o aprendizado da profissão a partir de seu exercício possibilita configurar como vai sendo construído o processo de aprender a ensinar". Nesse sentido, o estágio supervisionado deve ser um momento salutar na formação do futuro professor, possibilitando a esse uma ampla possibilidade de experiências que fundamenta a sua formação e o capacita ao exercício da docência, relacionando teoria e prática, permitindo a reflexão sobre a própria prática, constituindo um profissional aberto as necessidades e desafios do contexto educativo. 


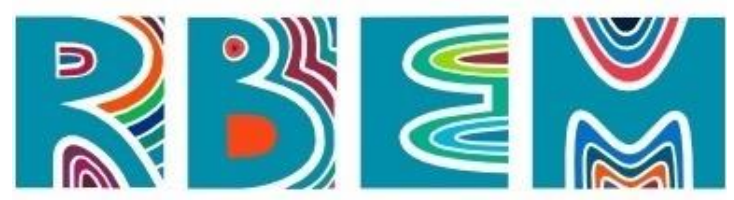

REVISTA BAIANA DE EDUCAÇÃO MATEMÁTICA

A partir dessas reflexões, faz-se necessário analisar a prática do estágio supervisionado, identificando as suas contribuições, como os desafios desse momento na formação do futuro professor.

\section{As Contribuições do Estágio Supervisionado na Formação Docente}

O Estágio Supervisionado se apresenta como um momento significativo de conexão do graduando com a escola, campo principal de atuação do futuro licenciado. Esse momento deve propiciar a observação, investigação e reflexão do futuro professor, numa perspectiva crítica que possibilita perceber o espaço educativo da escola como um campo amplo de experiências, visando o ensino e a aprendizagem.

Nesse contexto o futuro professor é lançado a olhar o campo profissional além dos muros da universidade, adentrar e se aventurar no campo profissional, no espaço educativo, marcado por suas especificidades e demandas. Nessa perspectiva é importante a figura do orientador de estágio, como um mediador durante as vivências propiciadas pelo estágio, que irão contribuir com o aprendizado do graduando, possibilitando um espaço de troca e reflexão sobre os dados observados e experenciados.

Durante o curso de graduação começam a ser construídos os saberes, as habilidades, posturas e atitudes que formam o profissional. Em períodos de estágio, esses conhecimentos são ressignificados pelo aluno estagiário a partir de suas experiências pessoais em contato direto com o campo de trabalho que, ao longo da vida profissional, vão sendo reconstruídos no exercício da profissão. (ALMEIDA e PIMENTA, 2014, p. 73)

Teixeira e Cyrino (2013) apresentam um estudo sobre o estágio supervisionado na licenciatura em matemática realizando um apanhado de dissertações e teses a respeito da temática, apresentando um panorama das pesquisas brasileiras. Segundo esse estudo o estágio supervisionado pode agregar a formação do futuro professor, permitindo o contato desse com a escola, possibilitando a construção de aprendizagens sobre a docência e o campo profissional.

O estágio permite relacionar os estudos teóricos da graduação com os aspectos práticos no exercício da docência, como a experiência de vivenciar, analisar e refletir sobre a identidade da profissão docente e os aspectos que envolve o planejamento, a avaliação e a interação com os educandos. 


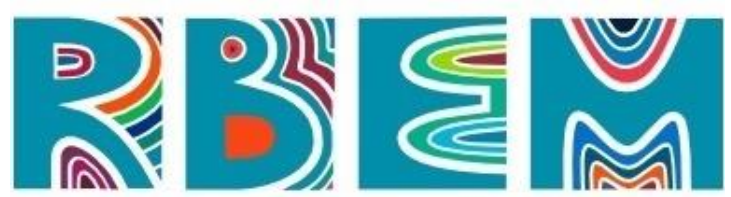

REVISTA BAIANA DE EDUCAÇÃO MATEMÁTICA

É preciso estabelecer um preparo que proporcione um conhecimento válido e gere uma atitude interativa e dialética que leve a valorizar a necessidade de uma atualização permanente em função das mudanças que se produzem; a criar estratégias e métodos de intervenção, cooperação, análise, reflexão; a construir um estilo rigoroso e investigativo. Aprender também a conviver com as próprias limitações e com as frustrações e condicionantes produzidos pelo entorno, já que a função docente se move em contextos sociais que, cada vez mais, refletem forças em conflito. Isso significa que as instituições ou cursos para a formação inicial deveriam ter um papel decisivo na promoção não apenas do conhecimento profissional, mas de todos os aspectos da profissão docente, comprometendo-se com o contexto e a cultura em que esta se desenvolve (IMBERNÓN, 2014, p. 63-64).

Por meio da vivência do estágio supervisionado o futuro professor pode identificar algumas dificuldades que poderá vivenciar no início da carreira, sendo importante para repensar as suas ideias iniciais sobre ela, abrindo espaço para a continuidade de sua formação durante todo o exercício profissional, ao mesmo tempo compreendendo qual o papel que irá desempenhar no ambiente educativo. "Por isso é que, na formação permanente dos professores, o momento fundamental é o da reflexão crítica sobre a prática. É pensando criticamente a prática de hoje ou de ontem que se pode melhorar a próxima prática". (FREIRE, 1996, p. 38-39). Quando esse conceito é desenvolvido e refletido desde o estágio supervisionado, isto possibilitar que as observações e as vivencias no campo educativo, contribuam com a autoavaliação em prol do seu aprimoramento profissional e humano, trazendo um olhar crítico e reflexivo sobre os diversos aspectos que envolve a identidade docente, como a produção, o desenvolvimento, a mobilização, a ressignificação e a validação dos diferentes saberes docentes.

Neste enfoque, o estágio supervisionado deve ser considerado como ponto de convergência, levando o estagiário a se preparar para enfrentar o mundo do trabalho, além de contribuir para a formação de sua consciência histórica que deverá ter como princípio articulador a práxis pedagógica, movimento dialógico entre o conhecimento que se converte em ação transformadora e a conversão da ação em conhecimento (LIBÂNEO, 1999, p. 32).

No ensino de matemática, como de outras áreas de conhecimentos, a prática do estágio supervisionado permite que o futuro professor possa identificar as necessidades dos educandos e aprofundar a investigação sobre os conceitos que envolvem cada conteúdo, como também os princípios que regem a sua organização, incluindo as ideias fundamentais da matemática a serem desenvolvidos na educação básica, refletindo sobre o planejamento, identificando a importância da abordagem metodológica, articulando aspectos teóricos e 


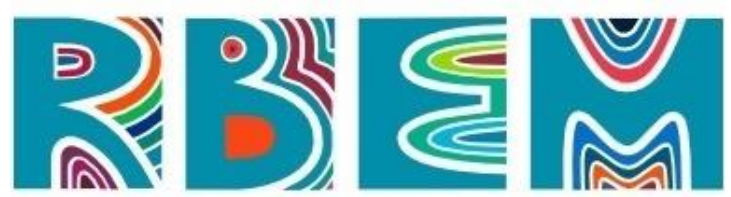

REVISTA BAIANA DE EDUCAÇÃO MATEMÁTICA

didáticos do ensino de um conteúdo matemático, visando a superação concepção tradicional, buscando estratégias pedagógica que parta de situações concretas e significativas aos estudantes, como situações-problemas que envolvam investigações ou mesmo projetos matemáticos.

No campo da matemática, o estágio supervisionado passa a ser um momento profícuo de aprendizagem, tanto para a instituição de ensino superior, uma vez que tem um campo fértil para novas pesquisas, como para o futuro professor, pois permite a esse identificar as interações dos educandos com os conceitos matemáticos, discutir as dificuldades apresentadas por eles, conhecer a metodologia implementada pelo professor, repensando criticamente sobre as ações e intervenções necessárias que possam propiciar o desenvolvimento de um trabalho significativo com a matemática, proporcionando a aprendizagem dos estudantes dos conceitos selecionados pelo professor para a aprendizagens dos estudantes, de forma que o educando passa a fazer uso social desse conhecimento no seu contexto, contribuindo com o desenvolvendo de seu espírito crítico, investigativo e a sua cidadania.

As contribuições advindas do estágio supervisionado não interferem apenas nos estudantes de graduação, mas envolvem todos os sujeitos que participam de sua ação, incluindo a instituição que recebe o estagiário, o professor orientador e toda a equipe da escola e da instituição superior envolvida. Isto traz a possibilidade de construção de parcerias significativas que contribui com a formação desse futuro professor. Esse processo, se construído de forma dialógica e colaborativa, entre a instituição de Ensino Superior e a escola, pode trazer inúmeros benefícios, uma vez que, a questões práticas serão refletidas a partir de referências teóricos, trazendo reflexões que podem trazer respostas a indagações reais de dificuldades enfrentadas durante a aula, tanto pelos futuros professores, quanto pelos professores da escola, em uma perspectiva de ensino prático, reflexivo, investigativo e participativo, envolvendo a parceria entre a escola e a universidade.

\section{A Prática do Estágio Supervisionado no Contexto da Educação Remota}

Com a pandemia de COVID 19 no ano de 2020, a humanidade passou a ter que ressignificar seu modo de vida e as relações humanas. Devido a necessidade de distanciamento social para se evitar a propagação do vírus, o mundo sente os reflexos econômicos, sociais, políticos e culturais advindos desse fenômeno. Dentre esses aspectos da 


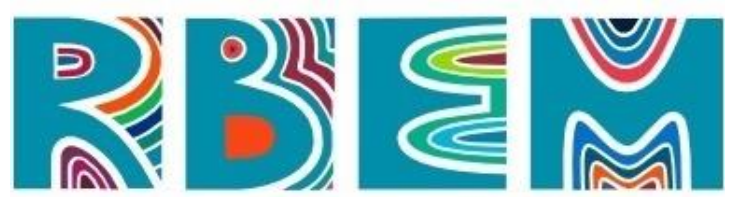

REVISTA BAIANA DE EDUCAÇÃO MATEMÁTICA

vida humana que sofreram a influência da pandemia, se encontra a educação, que necessitou se reinventar diante deste quadro, adotando o ensino remoto, mediado pelas novas tecnologias.

Como professores e estudantes somos incumbidos a remodelar as práticas para a continuidade da oferta escolar por meio do ensino remoto. As universidades enfrentaram os problemas decorrentes da desigualdade de acesso e condições para a inclusão digital, a ausência de formação para o domínio das diferentes práticas digitais, além de aspectos estruturais e de gestão do conhecimento. (SOUZA, FERREIRA, 2020, p.10)

Um dos grandes desafios desse contexto educacional é garantir o acesso de todos a educação, pois ainda há uma exclusão digital muito forte no país, além das dificuldades econômicas e falta de preparo das famílias em acompanhar os estudos de seus filhos e a formação dos professores para a mediação da aprendizagem no ensino remoto. Nesse contexto desafiador que a educação se encontra a questão da formação dos futuros professores e a prática do estágio supervisionado sofre interferência desse novo contexto que se apresenta. Com essa complexidade do momento foi necessário reinventar a proposta e o oferecimento desse momento aos estudantes de licenciatura.

Com efeito, a suspensão das atividades letivas presenciais, por todo o mundo, gerou a obrigatoriedade dos professores e estudantes migrarem para a realidade online, transferindo e transpondo metodologias e práticas pedagógicas típicas dos territórios físicos de aprendizagem, naquilo que tem sido designado por ensino remoto de emergência. (MOREIRA; HENRIQUES, BARROS, 2020, p. 352).

Foi pensando justamente nesse processo tão complexo vivenciado pela pandemia e visando trazer dados práticos para análise dialogando com as contribuições dos autores abordados nesse estudo que apresento a experiência sobre o estágio supervisionado numa escola municipal de ensino fundamental da cidade de São Paulo, situada na zona leste da capital. Essa unidade escolar possui 1071 estudantes matriculados no Ensino Fundamental (anos iniciais e finais), e Educação de Jovens e Adultos (EJA). A escola trabalha com uma proposta pedagógica diferenciada que é a polivalência, onde os educandos do Ensino Fundamental II e EJA passam a ter o acompanhamento pedagógico com um único professor que se torna polivalente, trabalhando as diversas áreas do saber, num trabalho colaborativo de formação entre seus pares. Nessa proposta pedagógica da polivalência amplia e fortalece o vínculo afetivo entre professor e estudante, facilitando essa aproximação entre o conhecimento historicamente estruturado. A formação entre os pares é organizada através dos 


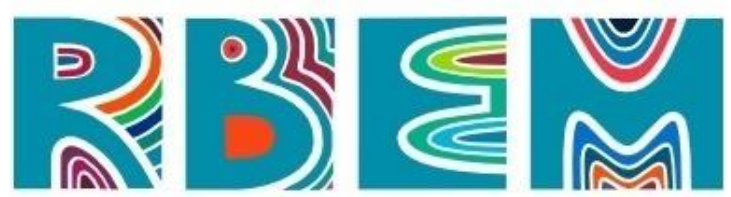

REVISTA BAIANA DE EDUCAÇÃO MATEMÁTICA

grupos de estudo, de forma a favorecer o vínculo entre professor e estudante, e entre professor e professores da unidade escolar, contribuindo com o processo de aprendizagem dos estudantes e dos próprios professores da escola, uma vez que a elaboração das aulas é discutida e organizada entre os pares de mesmo ano com os especialista, fomentando de forma intencional que os conhecimentos da área e as dificuldades dos educandos sejam o foco do trabalho.

A organização da proposta pedagógica da polivalência prevê que em cada ano tenha um professor de cada área. São três turmas de cada ano, na atribuição se atribui uma turma para um docente com formação em linguagens e códigos, outro com formação em humanas e outro formado na área de exatas. Essa organização visa o diálogo entre as áreas e que os docentes possam realizar trocas dentro do grupo de estudo, onde eles ensinam e aprendem concomitantemente, trocando experiências e planejando as ações pedagógicas coletivamente, na perspectiva de um ensino interdisciplinar e contextualizado.

Devido esse trabalho diferenciado, a escola tem sido muito procurada pelos estudantes de licenciatura e se tornado referência no acolhimento desses, além da própria localização da unidade, que se encontra próxima a uma estação do metrô, favorecendo o deslocamento dos estagiários e ao mesmo tempo, por se sentirem acolhidos e convidados a participar de todo processo reflexivo de organização do trabalho dos professores, em virtude da proposta pedagógica da polivalência.

Nesse contexto pandêmico, a prática de estágio na unidade foi ressignificada pela gestão escolar, que por meio da coordenação pedagógica acolheu esses estudantes, buscando ampliar a comunicação, ouvindo suas expectativas e fazendo a apresentação da proposta pedagógica da escola, proporcionando o livre acesso desse estagiário ao Projeto Político Pedagógico da unidade e ao planejamento dos professores.

A ação na sala de aula de planejamento e aplicação deste planejamento é uma relação de participação e apropriação de conhecimentos, por parte do estagiário e alunos da educação básica. Tem um lugar de destaque no processo formativo, pois é nesse estágio que o licenciado encontra o contexto natural de ensino: a aula. Essa situação de intervenção e (re) conhecimento da realidade é decisiva para o processo de reflexão da práxis educacional. $\mathrm{O}$ ensino, por meio da regência de classe, é uma das ações formativas do protagonismo profissional, espaço de exercício da autonomia docente e de assunção da autoridade profissional do estagiário (SOUZA, MARTINS, 2012, p.14). 


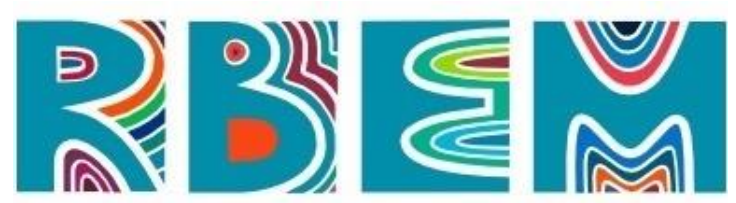

REVISTA BAIANA DE EDUCAÇÃO MATEMÁTICA

Nesse movimento, os estagiários participam dos momentos de horário coletivo de formação, eles são apresentados a equipe docente e iniciam a sua participação naquele espaço que se propõem ser dialógico, buscando sempre uma resposta conjunta para as situações que são propostas a partir da prática: dificuldade enfrentada pelo professor no desenvolvimento da aula, estudo de um conceito para aprofundar ou para buscar uma estratégia mais adequada aos estudantes daquela turma, análise da proposta e da aula feita pelos professores e implementada na sala de aula, enfim situações que possibilitam refletir sobre a prática. No estágio dessa unidade escolar, o acadêmico acompanha as diversas turmas nas aulas de matemática e experencia alguns momentos com as aulas das outras disciplinas, buscando compreender a dinâmica da polivalência. Os estudantes da escola tinham acesso as atividades planejadas pelos professores e estagiários durante as aulas, sendo disponibilizado esse conteúdo na plataforma virtual. Para isto, a escola utiliza a plataforma google classroom, uma sala de aula virtual, ao qual os professores interagem e disponibilizam materiais e situações de aprendizagem aos estudantes que estão inseridos nessa plataforma para acompanhar o processo pedagógico utilizado pela escola.

Outra prática significativa da escola, que é acompanhada pelos estagiários, são as aulas interativas virtuais realizadas pela plataforma google meet, onde os professores trazem "' as propostas que foram desenvolvidas para este espaço virtual, de maneira que possam dialogar com os educandos, propiciando situações e experiências de aprendizagem. Nesse movimento, os estagiários acompanham essas interações, refletindo sobre esse processo mediado pelas tecnologias. Essa experiência é significativa aos graduandos, pois permite a eles identificar as potencialidades das ferramentas tecnológicas utilizadas na mediação para o desenvolvimento das aprendizagens dos estudantes daquela turma, naquele contexto. As regências vão se moldando a partir das aproximações entre o professor e estagiário, de maneira que ambos possam se beneficiar, ou seja, o estagiário se beneficia da experiência da prática do professor e esse dos conhecimentos acadêmicos mais atuais.

Com o acompanhamento remoto, os estagiários possuem um momento com os professores da escola e com a coordenação para discutir as questões que envolve o ensino remoto e o processo de aprendizagem dos educandos, sendo um momento rico de troca e interação, contribuindo com um aprendizado coletivo. Nesse movimento, os estagiários participam do processo de planejamento, articulando situações de aprendizagem com os 


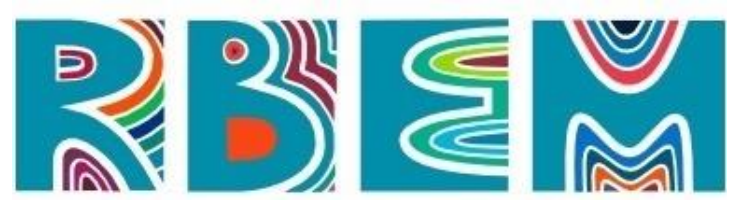

REVISTA BAIANA DE EDUCAÇÃO MATEMÁTICA

docentes, que concede essa abertura ao diálogo e a troca, possibilitando essa relação entre a teoria e prática.

Essa relação tem sido intensificada com a prática do estágio por meio de trocas entre a escola e os estagiários. Nessa experiência ressalta-se o diálogo frutífero entre os estudantes de licenciatura em matemática e os professores da escola. No contexto da unidade escolar os professores apresentam dificuldades relacionadas ao ensino de matemática. Com o projeto de polivalência, os professores com formação inicial em outras áreas necessitam estudar, revisar e se apropriar dos conceitos matemáticos e de saberes didáticos e metodológicos para desenvolver uma proposta de ensino e aprendizagem adequada que contribua efetivamente com a aprendizagem dos estudantes.

No contexto da escola analisada observa-se grandes dificuldades dos estudantes com relação a matemática, sendo uma área desafiadora de ensino aos professores, tanto nos aspectos de conteúdo como nos didáticos. A partir dessa dificuldade, a coordenação pedagógica tem impulsionado a formação permanente nos momentos de horário coletivo formativo e aberto espaço aos estagiários para trazer colaborações do mundo acadêmico para a discussão com todo o grupo, como o estudo de caso e análise das atividades dos educandos, tem aberto espaço para impulsionar o diálogo, a reflexão e a construção de estratégias coletivas, por meio da relação entre professores e estagiários, onde ambos são beneficiados por essa experiência, por meio da prática e das contribuições teóricas advindas desses estagiários, tem sido possível ressignificar o processo de aprendizagem em matemática, favorecendo a formação profissional.

Esse movimento tem contribuído com a escola e com a formação dos futuros professores, pois esses deixam de ser meros observadores da prática desenvolvidas pelos docentes da escola e de preenchedores de relatórios, exigência legal para a conclusão do curso, e passam a ser sujeitos integrantes do processo, onde aprendem juntos com os demais professores da escola. É perceptível a contribuição dessa parceria entre professores e estagiários em relação ao ensino de matemática, por meio das devolutivas compartilhadas nos momentos coletivos, pois esse processo permite a ampliação de ideias, ajustes das situações pensadas em função das características dos alunos e do próprio contexto da escola - ser polivalente, ou seja, uma negociação constante de sentido entre os participantes, mostrando 


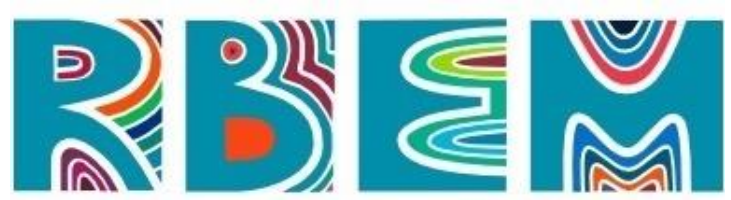

REVISTA BAIANA DE EDUCAÇÃO MATEMÁTICA

um trabalho integrado, visando a melhoria no desenvolvimento profissional dos envolvidos e das aprendizagens dos alunos da escola.

Mesmo com os desafios do trabalho educacional no contexto pandêmico e da educação remota, o estágio supervisionado tem ocorrido levando em consideração esse novo momento desafiador, possibilitando a ressignificação dos processos educativos e a troca frutífera entre estudantes de licenciatura, professores e educandos da educação básica, onde se fortalece o vínculo das universidades com a escola, entre professores da unidade escolar e os estagiários, possibilitando ganhos significativos na formação inicial do futuro professor, mas também na formação continuada dos profissionais dessa escola, pela própria troca de informações e de conhecimentos que acontece entre eles, trazendo a experiência da prática desses professores e os as próprias discussões que se estabelece na instituições de Ensino Superior que acompanham estes alunos a partir da observação e registros dessas vivências.

$\mathrm{Na}$ unidade escolar apresentada identifica-se um intenso esforço da coordenação pedagógica e de toda equipe escolar para acolher e ampliar os vínculos entre professores, estudantes e estagiários, permitindo a reflexão e a troca do conhecimento nesse momento vivenciado pela pandemia. É a ressignificação da prática nesse contexto que permite a qualificação do processo, ampliando as relações, a comunicação e o aprendizado coletivo.

\section{Desafios e entraves para a prática do estágio supervisionado.}

Já vimos que o estágio supervisionado está presente na legislação educacional e no projeto pedagógico dos cursos de licenciatura como uma obrigatoriedade na formação dos futuros professores. Vimos também a importância dessa prática na formação do futuro profissional, como um momento propício de relacionar a teoria e a prática e constituir a identidade desse profissional por meio da experiência prática e a vivência de situações desafiadoras do contexto educacional.

[...] o saber docente não é uma coisa que flutua no espaço: o saber dos professores é o saber deles e está relacionado com a pessoa e a identidade deles, com a sua experiência de vida e com sua história profissional, com as suas relações com os alunos em sala de aula e com os outros atores escolares na escola, etc. (TARDIF, 2002, p. 11)

Apesar das grandes potencialidades que o estágio supervisionado oferece ao graduando em formação, se faz necessário investigar e destacar alguns entraves que o limita ou dificulta para que esse momento seja realmente significativo. Um dos desafios presentes 


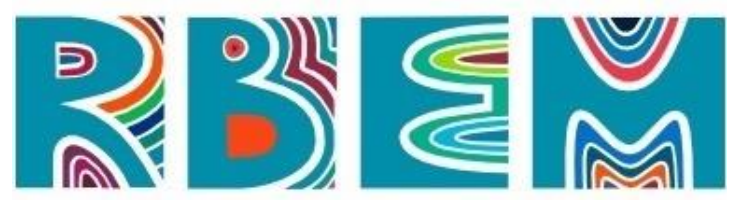

REVISTA BAIANA DE EDUCAÇÃO MATEMÁTICA

nesse contexto pandêmico da COVID 19 é a questão do isolamento social que interferiu intensamente nas práticas educativas e relações entre os sujeitos, dificultando a colaboração e a integração entre os participantes da prática pedagógica.

Nesse novo cenário muitas unidades restringiram o oferecimento de estágio, além das dificuldades de se acompanhar as atividades remotas, onde muitas vezes o acesso é restrito aos estudantes e professores, dificultando esse acesso aos usuários externos. A falta de interação presencial é outro aspecto desafiador, pois nesse novo momento a escola tem de aprender em desenvolver esse vínculo de forma remota.

Uma das questões apresentadas pelos estagiários, diz respeito a documentação exigida para a garantia do estágio, como o Termo de Compromisso de Estágio (TCE), o seguro obrigatório e a documentação de convênio entre instituição superior e escolar. É uma documentação necessária, mas devido os trâmites legais de algumas universidades, esse processo tende a ser moroso, desestimulando alguns estagiários. É fundamental refletirmos que essa documentação é importante e necessária, que deve servir para registrar o percurso, não de forma burocrática, mas favorecendo o registro do processo de formação do estudante, fomentando novas reflexões ou investigações.

Esse processo de receber o estagiário na unidade escolar observada é ressignificado, no sentido de perceber a presença desse sujeito como um aprendiz, que aprende na e com a escola e colabora com ela, ajudando a pensar coletivamente as estratégias de ensino e estabelecendo uma ponte entre os conhecimentos produzidos na prática com os que estão sendo fomentados pela prática.

Conforme Alburquerque e Silva (2006, p.9) “A grande lição que se busca deixar para o aluno é o fato de que não se pode aprender tudo de uma só vez e em tão pouco tempo. $\mathrm{O}$ mais importante será analisar cada tarefa que lhe for atribuída e procurar com zelo desempenhá-la".

Outro entrave é que o estagiário pode passar por situações de ansiedade e estresse devido aos desafios enfrentados, ao qual na universidade não teve a possibilidade de discutir e nem tão pouco vivenciá-los na prática. Situações como a precariedade das escolas, indisciplina, violência e dificuldade de desenvolver o trabalho pode acarretar essas situações e sentimentos ao estagiário, que necessita ressignificar sua visão e lidar com situações que 


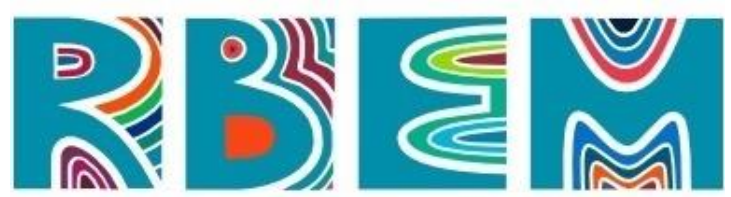

REVISTA BAIANA DE EDUCAÇÃO MATEMÁTICA

fazem parte do cotidiano de grande parte dos professores atualmente e carecem de novas reflexões e de novas respostas para o contexto atual.

Outro aspecto relevante, se encontra nos problemas de orientação por parte dos supervisores de estágio e do pessoal envolvido na organização desses estágios. Muitas vezes esses profissionais possuem uma demanda excessiva de trabalho, não conseguindo dar um acompanhamento necessário ao estagiário, até mesmo pelo número de alunos que possuem. A orientação é fundamental no processo do estágio, concedendo apoio pedagógico e emocional ao futuro professor, mas também dar devolutiva para este estagiário no decorrer do processo, de maneira que ele perceba que os dados coletados servem a um propósito, apoiá-lo na sua constituição de futuro docente e com isto cabe referenciar Albuquerque e Silva, 2006 quando trazem que "Cabe ao professor supervisor do estágio orientar o aluno no sentido de que ele alcance uma maturidade necessária, sem que fique absolutamente estressado ou ansioso pelo fato de ter pouco tempo para a realização do estágio" (ALBURQUERQUE; SILVA. 2006, p.9).

Com essas reflexões queremos dizer que as práticas de estágio supervisionado devem ser permeadas por experiências significativas de observação, análise, reflexão e interação entre os sujeitos do processo educativo. Os entraves devem ser analisados e superados por meio de estratégias que valorize o processo, valorizando os aspectos qualitativos e detrimento dos quantitativos.

\section{Considerações Finais}

Por meio do estudo bibliográfico e da análise da prática do estágio supervisionado em uma unidade escolar pública foi possível suscitar questionamentos e reflexões a respeito da importância dessa prática na formação dos futuros professores, além de analisar o estágio supervisionado no contexto da educação remota imposta pela situação da pandemia de COVID 19.

O estágio supervisionado pode contribuir muito com a formação do futuro profissional docente, desde que ultrapasse a perspectiva de uma atividade burocrática que visa apenas as exigências da conclusão do curso escolhido. Nesse sentido, faz-se necessário um acompanhamento e orientação de estágio qualitativa, que apoie o estudante, concedendo espaço para escuta e reflexão, proporcionando subsídios para a sua formação. É por meio da 


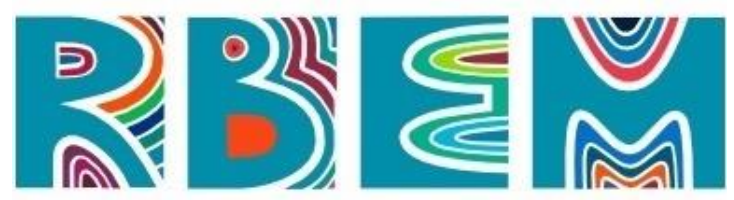

REVISTA BAIANA DE EDUCAÇÃO MATEMÁTICA

relação do estagiário com o campo da prática profissional e dos estudos desenvolvidos na academia que esse sujeito vai se constituindo enquanto futuro docente.

Devido ao contexto pandêmico a prática de estágio supervisionado necessitou ser ressignificada, incorporando o uso das novas tecnologias no acompanhamento das propostas pedagógicas e interação com as práticas escolares. Esse momento novo e desafiador a escola contribui para o futuro profissional perceber a atividade docente como dinâmica, que deve ser incorporada e repensada devido os novos contextos que se apresentam, ultrapassando uma concepção de proposta pronta e acabada.

Essa perspectiva nos conduz a concepção freireana de inacabamento, onde somos seres que estamos num contínuo processo de formação e constituição de nossa identidade. A atividade docente perpassa pelo contínuo processo de formação, que visa a reconstrução permanente das estratégias atendendo as necessidades do momento.

Desenvolver o estágio supervisionado no contexto pandêmico na educação remota é um desafio intenso, que demanda novos olhares e perspectivas, buscando ampliar a interação entre os sujeitos do processo educativo com mediação das tecnologias, permitindo uma reflexão do momento e construção de práticas que favoreça o processo de aprendizagem nesse contexto tão desafiador.

O presente trabalho acadêmico não esgota o assunto, mas apresenta reflexões a respeito da importância do estágio supervisionado na formação do futuro docente, como a necessidade de qualificação desse momento formativo, intervindo nos entraves a um processo mais significativo da formação profissional. As perspectivas de estudos futuros perpassam pela necessidade de ampliação da investigação sobre como estabelecer maior relação estagiário professor, objetivando o planejamento conjunto e a qualificação desse processo.

Outros estudos e reflexões fazem-se necessários para o repensar da própria prática como desenvolvimento de ações e políticas públicas que favoreçam o processo de formação no estágio supervisionado na perspectiva da constituição de um profissional crítico, que reflita sobre a sua própria prática e que esteja aberto as transformações, sendo capaz de inovar e responder as necessidades educativas.

\section{Referências Bibliográficas}




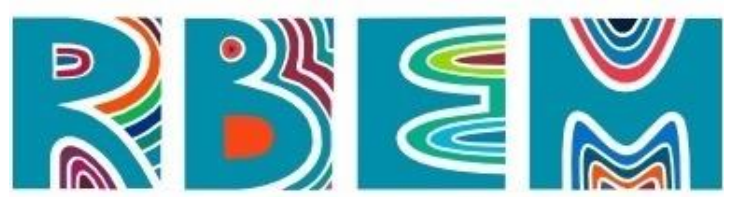

REVISTA BAIANA DE EDUCAÇÃO MATEMÁTICA

ALBUQUERQUE, Lúcia Silva; SILVA, Elisangela Medeiros. Pontos positivos e negativos do estágio na formação profissional dos estudantes de Ciências Contábeis da cidade de Caruaru-PE. Encontro da Associação Nacional de Pós-Graduação e Pesquisa em Administração-Enanpad, v. 30, 2006.

ALMEIDA, Maria I.; PIMENTA, Selma G. Estágios supervisionados na formação docente. São Paulo: Cortez, 2014.

BRASIL. Lei n. 11.788, de 25 de setembro de 2008. Dispõe sobre o estágio de estudantes. Diário Oficial da União, 2008.

FIORENTINI, Dario; CASTRO, Franciana Carneiro de. Tornando-se professor de matemática: $O$ caso de Allan em prática de ensino e estágio supervisionado. In: FIORENTINI, Dario (Org.). Formação de Professores de Matemática: Explorando novos caminhos com outros olhares. Campinas: Mercado Letras, 2003. Cap. 4. p. 121-156.

FREIRE, P. Pedagogia da Autonomia. Saberes necessários à prática educativa. Coleção Leitura. São Paulo: Paz e Terra, 1997.

LISOVSKI, L. A; TERRAZAN, E. A. As instituições de ensino superior e as escolas de educação básica na formação inicial dos professores de ciências naturais e biologia. In: VI ANPEDSUL, Santa Maria: UFSM, 2006.

MOREIRA, José António Marques; HENRIQUES, Susana; BARROS, Daniela. Transitando de um ensino remoto emergencial para uma educação digital em rede, em tempos de pandemia. Dialogia, São Paulo, n. 34, p. 351-364, jan./abr. 2020. DOI https://doi.org/10.5585/dialogia.n34.17123. Disponível em: https://periodicos.uninove.br/index.php?journal=dialogia\&page=article\&op=view\&path $\% 5 \mathrm{~B}$ $\% 5 \mathrm{D}=17123 \&$ path\%5B \%5D=8228. Acesso em: 13 jul. 2021.

RIOS, Terezinha Azerêdo. Ampliar o diálogo de saberes para a docência. In: FRANCO, Maria Amélia Santoro; PIMENTA, Selma Garrido. (Orgs.). Didática: embates Contemporâneos 3. ed. São Paulo: Edições Loyola, 2014. p.101-130.

SARMENTO, Teresa; ROCHA, Simone Albuquerque da; PANIAGO Rosenilde Nogueira. Estágio curricular: o movimento de construção identitária docente em narrativas de formação. Revista Práxis Educacional, Vitória da Conquista - Bahia - Brasil, v. 14, n. 30, p. 152-177, out./dez. 2018. DOI https://doi.org/10.22481/praxis.v14i30.4365. Disponível em: http://periodicos2.uesb.br/index.php/praxis/article/view/4365/3493. Acesso em: 15 jul. 2021.

SOUZA, Ester Maria Figueiredo; FERREIRA, Lúcia Gracia. Ensino remoto emergencial e o estágio supervisionado nos cursos de licenciatura no cenário da Pandemia COVID 19. Revista Tempos e Espaços em Educação, v. 13, n. 32, p. 85, 2020. 


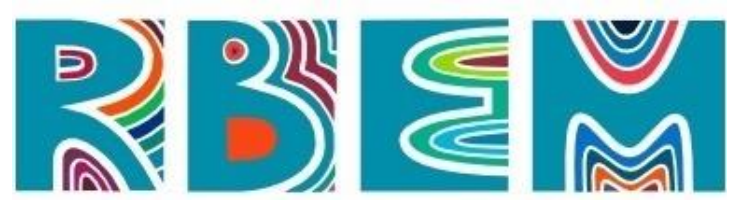

REVISTA BAIANA DE EDUCAÇÃO MATEMÁTICA

SOUZA, Ester Maria de Figueiredo Souza. MARTINS, Angela Maria Gusmão Santos. Estágio supervisionado nos cursos de licenciatura: pesquisa, extensão e docência. Revista Práxis Educacional, Vitória da Conquista, Bahia, Brasil, v. 8, n. 13, p. 143-156, 2012. Disponível em: http://periodicos2.uesb.br/index.php/praxis/article/view/711/597. Acesso em: 03 abr. 2015.

IMBERNÓN, Francisco. Formação docente e profissional: formar-se para a mudança e a incerteza. São Paulo: Cortez, 2014.

LAKATOS, E. M.; MARCONI, M. A. Fundamentos de Metodologia Científica. São Paulo, SP: Atlas 2003.PIMENTA, Selma. Garrido; LIMA, Maria Socorro. Estágio e docência. 6. ed. São Paulo: Cortez, 2011.

LIBÂNEO, J.C. Pedagogia e pedagogos, para quê? São Paulo: Cortez, 1999.

Lima, Maria da Glória Soares Barbosa. Sujeitos e saberes, movimento de autorreforma da escola. In: Mendes Sobrinho, José Augusto de Carvalho; Carvalho, Marlene Araújo de (Orgs.). Formação de professores e práticas docentes: olhares contemporâneos. Belo Horizonte: Autêntica, 2006. p. 31-39.

SEVERINO, A. J. Metodologia do Trabalho Científico. São Paulo, SP: Cortez, 2007.

TARDIF, M. Saberes docentes e formação profissional. Petrópolis: Vozes, 2002.

TEIXEIRA, Bruno Rodrigo; CYRINO, Márcia Cristina de Costa Trindade. O estágio supervisionado em cursos de licenciatura em Matemática: um panorama de pesquisas brasileiras Supervised internship in mathematics: a view of brazilian researches. Educação Matemática Pesquisa: Revista do Programa de Estudos Pós-Graduados em Educação Matemática, v. 15, n. 1, 2013.

Artigo submetido em: 21/07/2021

Artigo aceito em: 14/09/2021 